\title{
CONTEXTUAL FACTORS INFLUENCING THE DESIGN AND MANAGEMENT OF HEALTH INFORMATION SYSTEMS' INTEROPERABILITY
}

\author{
Grace Kobusinge ${ }^{1,2}$ \\ ${ }^{1}$ Gothenburg University, Gothenburg, Sweden \\ ${ }^{2}$ Makerere University, P.O. Box 7062 Kampala, Uganda
}

\begin{abstract}
Due to their renowned great information processing and dissemination power, Health information systems (HIS) can readily avail past patient medical information across the continuum of care in order to facilitate ongoing treatment. However, a number of existing HIS are designed as vertical silos with no interoperability onuses and therefore, cannot exchange patient information. At the same time, there is limited knowledge about the intricacies and factors that surround HIS' interoperability implementations. This study therefore, employs an institutional lens perspective to investigate contextual factors influencing HIS' interoperability designing. Through this perspective, seven contextual factors were arrived at institutional autonomism, intended system goals, existing health-information-systems, national HIS implementation guidelines, interoperability standards, policy and resources in terms of money and labour. A further study implication is the use of institutional lens in making sense of the institutions' context of integration in order to discover salient factors that might influence health-information-systems' interoperability designing.
\end{abstract}

\section{KEYWORDS}

Health Information Systems' Interoperability, Design and Management, Contextual Factors.

\section{INTRODUCTION}

Heath information system (HIS) implementation has of recent been top on agenda of most federal governments and healthcare institutions [1]. This is because HIS have proved to be useful in managing health information $[2,3]$ and still promise among others improved patient care and coordination as they become more interoperable [4-6]. HIS are interoperable if they can work together to effectively deliver healthcare within and across organizational boundaries [7]. Currently, a number of HIS are non-interoperable, given that they are designed as vertical silos [8-10]. Consequently, in efforts to aid ongoing treatment, several healthcare centers experience patient information exchange challenges $[11,12]$. Nonetheless, to overcome such challenges, [8] among other authors call for the design and implementation of horizontally integrated health information systems.

However, there exists considerable research about interoperability and HIS integrated systems [8], but there is limited knowledge on the intricacies of their implementation processes [1, 13-15]. Yet according to [16] a system is as good as its implementation process. Therefore, to further understanding of the HIS implementation process intricacies, [17-22] emphasize the examination of salient contextual factors that influence the implementation process. Contextual factors are key

David C. Wyld et al. (Eds): ITCSE, NLCA, ICAIT, CAIML, ICDIPV, CRYPIS, WiMo - 2020 
features within the environment that influence the intervention [23]. They can either enable or hinder successful implementation of information communication systems [23, 24]. According to [25-27] successful information system interoperability implementations depend on the context of integration. They [25] and [27] state that the choice of an

interoperability principle greatly depends on the context of integration. An interoperability principle is a communication link between information systems that enables them to exchange information [27]. Therefore, a thorough analysis of the context of integration [25, 27] and the discovery of salient contextual factors might increase HIS interoperability implementations [28]. To better understand salient organizational and institutional factors [29] recommend the use of institutional theory in such studies. They assert that institutional theory helps researchers to analyze both internal and external factors influencing the implementation process. At the same time [30] calls for proper management of the entire context analysis process, and [31] argues for both management and designing of organizational interoperability. Indeed several authors argue for interoperability designing during system implementation [6, 32], and [15] argues for tactful management of the implementation process. Therefore, in order to improve understanding of the intricacies surrounding the design and management of HIS interoperability process, this study draws on institutional theory to examine contextual factors that influence such processes.

The structure of this paper is as follows: In the theoretical framing section, institutional theory is explored as a framework within which to analyze internal and external contextual factors that influence HIS interoperability implementations. The research approach section describes the study as an interpretative case study, and explains the data collection and analysis methods applied. Study findings are presented in the fourth section as contextual factors. This is followed by a discussion of identified contextual factors according to their degree of controllability and their influence on HIS interoperability implementations. The final section concludes the paper and proposes future works regarding contextual HIS interoperability management and designing.

\section{THEORETICAL FrAMING: INSTITUTIONAL THEORY}

Healthcare systems usually consist of a number of institutions [33], and according to [34] institutions are social structures that have attained higher degrees of resilience, and legitimacy. Institutions are composed of cultural-cognitive, normative, and regulative elements that together with other factors provide stability [34, 35]. Therefore according to institutional theory, organizations are influenced by both internal and external pressures within the environment in which they operate [36]. Accordingly, institutional theory helps in understanding inherent relationships among institutional mechanisms and other organizational factors [37]. Usually, prevailing coercive, mimetic and normative isomorphic forces largely shape the institution [38]. Whereby coercive forces are formal and informal political influences that institutionalize certain practices, mimetic forces are pressures to mimic other similar institutions, and normative forces are those associated with professionalization of organizational actors [38]. A number of researchers have used institutional theory, but this study has been inspired by [29] who used institutional theory to understand barriers to e-government interoperability, and [39] who used it to study enterprise architectures and interoperability in governments. Thus, this study employs institutional theory to analyse internal and external contextual factors that influence health institutions' legitimate behaviours [38] during the design and management of HIS interoperability. 


\section{RESEARCH APPROACH}

The study employed a case study perspective [40] where participants' responses were conceptualized to construct meaning according to the study objectives [41]. A case study perspective was chosen in order to explore and illustrate the HIS implementation phenomena in action [40, 42]. Through qualitative research methods that included; semi-structured interviews, document reviews and focused group meetings [40, 43] data was collected and analysed through the general inductive analysis method [44]. The inductive analysis method consisted of several phases, right from interview transcription to refinement of categories in relation to the study objectives [44].

\subsection{Case Study Setting and Description}

The case study investigated health information systems used across health facilities in Uganda. Uganda is a developing country in Africa that is highly embracing HIS use at most of its health facilities [45]. Health facilities in Uganda are either public or privately owned, and are at different regulatory levels; national/regional referrals, district hospitals and health-center IV-I respectively [45]. However, each health institution operates independently and can implement its own HIS, thus the numerous HIS in use within the country [46]. Particularly, for this study, participating HIS were identified through a field exploration of the implemented HIS within the country that was carried out from July 2017 to July 2018. Through this field exploration it was discovered that many systems were donor funded and would not go beyond the piloting stage whenever the funded project ended [47]. Therefore, stable health information systems that were sustainable and widely used across health facilities were singled out. Consequently, with insights from the ministry of health officials, five outstanding health information systems were considered for the study. They included Uganda-EMR, District Health Information System - DHIS2, HeleCare2x, Clinic master and Nganisha health information system as per their description in Table 1. Consequently, the study participants consisted of five ministry of health officials, fifteen systems developers, and seven projects managers for the identified HIS.

Table 1. Description of studied HIS.

\begin{tabular}{|c|c|}
\hline $\begin{array}{l}\text { Health } \\
\text { information } \\
\text { system }\end{array}$ & Description \\
\hline Uganda-EMR & $\begin{array}{l}\text { Uganda-EMR. This is customized 'Open-MRS' electronic medical records } \\
\text { system for Uganda. The ministry of health has recommended it to be the nation's } \\
\text { patient records' sys-tem. Pilot testing on the HIV-AIDS module are ongoing in } \\
\text { selected districts within the country. http://emrportal.mets.or.ug/ }\end{array}$ \\
\hline DHIS2 & $\begin{array}{l}\text { District Health Information System -DHIS2 is a health management system that } \\
\text { provides a logical platform for data entry, processing, and data presentation to } \\
\text { national planners" [33] }\end{array}$ \\
\hline HeleCare $2 x$ & $\begin{array}{l}\text { HeleCare2x: Customized for Uganda from Care2x, it is an Integrated Hospital } \\
\text { Information System that includes: Admission, Surgery, Outpatient, Nursing, } \\
\text { Wards, Pharmacy, Labs and Security among others [48]. It provides one } \\
\text { complete single patient record at the health facility. (http://care2x.org/). }\end{array}$ \\
\hline Clinic master & $\begin{array}{l}\text { Clinic master: this integrated health information management and medical billing } \\
\text { system automates patients' transactions at the clinic on a visit basis. It is mostly } \\
\text { used by private health institutions. https://clinicmaster.net/about-us/ }\end{array}$ \\
\hline Nganisha & $\begin{array}{l}\text { Nganisha health information system is an all-inclusive health management } \\
\text { information system that provides real time and complete patient health data at a } \\
\text { health facility. Current pilots are in government health facilities (western and } \\
\text { eastern Uganda) by health net chattered Uganda. } \\
\text { https://twitter.com/ugandahealthnet. }\end{array}$ \\
\hline
\end{tabular}




\subsection{Data Collection}

Data collection involved interviews, focus group discussions, and document reviews [43]. Semistructured interviews were used to generate deep and rich interactions during the interviews, whereby the researcher made sense of the interviews by constructing meaning. Interviews for project managers and system developers focused on extracting responses regarding external and internal salient factors onto which they based HIS implementation decisions. Whereas ministry of health officials' interviews focused on the kind of HIS in use, interoperability structures or policies in place and national HIS implementation guidelines in place. All interviews were recorded with permission and each session lasted approximately 70 minutes. System developers were interviewed more than once in order to get rich data and insights of what transpired during the HIS implementation process. In order to confirm what was reported in the interviews [41], key documents including Uganda e-health policy, HIS developers' websites and the national sector development plan were reviewed. In addition, this study adhered to ethical issues of confidentiality, integrity and anonymity [49].

\subsection{Data Analysis}

The data analysis stage consisted of several phases, with verbatim transcription [50] in the early phases. This was followed by reading the interview transcripts several times in order to make sense of the study objectives [44]. This analysis phase enabled the identification and construction of contextual factors that influence the design and management of HIS interoperability. Inspired by institutional theory the researcher identified respondent phrases that pointed to either an external or an internal need/pressure that influenced their HIS implementation decisions concerning interoperability. The last phase was to revisit the data in order to re-examine the identified working categories and refine them into final categories. Particularly, ten working categories were refined into seven final categories of contextual factors.

\section{Results}

This section presents seven contextual factors that influence the design and management of HIS interoperability as described below. These factors were determined from external and internal pressures that influenced the HIS implementation process according to institutional theory.

\subsection{Intended System Goals}

In order to fulfil their core values, institutions often implement information systems for smooth operations. However, in any system development process, the first phase is always focused on eliciting the requirements of the system [51]. For successful requirement elicitation [51] recommends a goal driven approach. Therefore, in consultation with the system users, designers look out for system requirements vs intended system goals. They ask questions like; why is the system being designed, and what is it going to serve. Within this phase the intended system users present their requests of what the system should offer, and to the designers these form system requirements. Ultimately, these system requirements mirror the intended goal of the system. The system is then designed according to the requirements presented by its intended users. For example, if the users' requirement were that the system should share data with other HIS, then it would be designed as interoperable else it would be designed with no focus on interoperability. This is evident in the following participants' verbatim quotes.

"Implementation decisions are made based on client needs", "Yes so it is more of demand driven, we build on demand" and "but if we have a requirement (need/goal) that it must talk to 
some other system, then we ensure we produce the right data either as input or output for any system."

Therefore, if interoperability is among system requirements, then it can inherently/purposively be designed [6] else it will be designed in future as need arises. Therefore, initial goals of the system/system requirements can greatly influence system design and implementation. They determine whether interoperability capabilities should be designed along or not [52].

\subsection{National HIS Implementation Guidelines}

Systems cannot interoperate unless interoperability capabilities are designed consciously into them, either inherently or at the time of need $[52,53]$. This implies that in order to have HIS that are interoperable, there ought to be standard HIS implementation guidelines for all participating systems [54, 55]. ISO-2004 standard asserts that any systems planning to integrate should do so according to prescribed methods [56] and according [57] organizations have to mutually agree to interact, though this tends to be hard in practice [58]. In Uganda, HIS developers are required to follow the current HMIS tools during system implementation as a minimum ministry of health directive. HMIS tools are local paper forms that are standardised specifically for data collection about key health indicators at health facilities. Therefore, authorities in a given country ought to enforce uniform HIS interoperability implementation guidelines, else every single HIS will be developed independently following institution specific guidelines. Below is a respondent verbatim quote about HIS implementation guidelines in Uganda.

"We had no regulatory framework, no policy, no standards, no interoperability framework, people just implement haphazardly without following any guidelines from the ministry."

However, all hope for Uganda is not lost as the design for an interoperability architecture is underway. Once the interoperability architecture is institutionalized and operationalized, all HIS developed in the country will be required to adhere to it, which could advance HIS interoperability implementations in the country. Here we clearly see coercive forces at play, when standard HIS implementation guidelines become a rule of thumb.

\subsection{Interoperability Standards}

Interoperability standards "facilitate seamless sharing of information between health information systems" [54, 59]. They could be messaging standards, terminology standards and general interoperability standards $[54,59]$ specifically, for healthcare they could include standard disease classifications and standardized electronic health records among others [54]. Enforcement of such uniform interoperability standards at national or institutional level might lead to implementation of interoperable HIS. The importance of interoperability standards is actually identified in the following respondent verbatim quotes:

"Mainly, we look at software development standards that allow interoperability, we use mainly REST." "As long as that system is compatible to some standard there can be a possibility of sharing data with the other systems." "... On top of what the users have requested, there are some standards."

In contrast, lack of uniform interoperability standards leads to the design of health information systems that are not interoperable [11], since they are designed following institution specific standards. This is reflected in the following respondent verbatim quote. "That is one of the main problems of systems we have been having, most of them have their own standards." Nevertheless, it is important to know the kind of data that needs to be shared, else each system 
will define its own, and there will not be a standard patient record to share. The importance of defining a standard patient record can be seen in the following participants' verbatim quotes.

"We are restricted in what to move." "We have tried to look for any document that defines that but in vain. All of them stop on the point of integration and interoperability but they don't narrow down on what should be shared."

\subsection{Institutional Autonomism}

According to [60] institutional autonomism can greatly influence the system integration process. In Uganda health institutions are either publically owned or privately owned [45]. The public owned are entirely under government leadership and the private ones are under institutional governance. Whereas public health institutions entirely implement government directives and recommended health systems, private institutions tend to be hesitant. A case in point is the Uganda Ministry of health directive to use DHIS2 system at all health facilities, whereas public health institutions use DHIS, private institutions rarely use it, as reflected in the following respondent verbatim quote.

“....all these health facilities are obliged to report ...whether private or public, but again the private clinics they do not report."

In most cases, autonomous institutions implement their own HIS and follow their own institutionspecific implementation guidelines. Due to institutional logics, [39] argues that organizations can implement their own systems, and can even mimic other systems. Such practises can increase system fragmentation and duplication, and can affect a countries' HIS interoperability plans. Consequently, the nation ends up having numerous silos HIS that are non-interoperable and cannot share/exchange health data. For example three of the studied Uganda systems (Nganisha, Clinic master and HeleCare 2x) are all focused on providing one complete single patient record at the health facility.

On the other hand collaboration among health institutions is a key ingredient to interoperability designing however, there is little coordination amongst healthcare units and little communication between different health information systems [61]. In effect, most institutions tend to own their health data and are not open to external discussions [6]. They usually consider their data as an institutional assert or are prohibited by donor specific regulation as evident in the following participants' verbatim quotes.

"There is no will to share in private hospitals, though the government wants to integrate health systems." "... ownership of the data is a big issue, each entity believe that they own there data and remember each entity is autonomous so there is a lot of negotiation that is involved."

"... We have asked how come they are not interoperable... this is given by the donor and they are not willing to integrate."

\subsection{Policy}

Due to coercive isomorphism, institutions are subjected to certain important laws or rules that govern them [62]. These laws could be in form of policies since a policy is a rule of law according to [63]. Regarding HIS implementations, policies could concern system development, system integration, data sharing and information exchange, security and privacy of sensitive health data among others. Such policies once institutionalized [55, 64] could help direct HIS 
interoperability implementations within a country. For example, Uganda has an operational ehealth policy within which all HIS in the country must be interoperable, and must integrate with DHIS2. DHIS2 is the countries' national aggregation system for key health indicators. For example, data sharing policies ought to take into consideration the sensitivity of health data, when it comes to cross boundaries exchanges. For example, due to the sensitivity of health data, HIS in Uganda are restricted from exchanging or even clouding patient medical information. In effect, policy regulations influence the way HIS are implemented, either as interoperable or as non-interoperable. The following are respondent verbatim quotes concerning the influence of policy to HIS interoperability implementations.

"...policy is one of those challenges." "...but the challenge comes in with policy, policy of Uganda especially health does not allow clouding patient information." what is restricting is not the technology but is policy and maybe human resource but technology-wise we are already there."

\subsection{Existing Health Information Systems}

Health information systems' interoperability is achieved when all participating systems are able to share and exchange health data amongst themselves [65]. However, interoperability is a capability $[31,53]$ which can be present or missing in a given system. It is therefore, important to scrutinize all existing HIS of their interoperability capabilities [66] in order to plan their compatibility with other systems [67]. According to [58] existing systems highly influence interoperability designing, they determine if a standard-approach can be taken or not. For instance, the Ministry of health of Uganda in 2018 carried out an e-health readiness assessment to examine existing HIS in order to determine those to scale out and those to eliminate.

“...in the interim period we wanted to look at the criteria.... For example EMRs what should they look at, before I approve an EMR to be used in the country ... to have a benchmark, to see how can we assess and agree whether we should adopt this or we feel this EMR has worked in five districts why can't we scale it up instead of having another one"

In addition, observed benefits from existing systems can lead to implementation of similar interoperable systems due to institutional mimetic forces. A case in point is the district health information system - DHIS2, which is taken as the countries' model system, and thus the proposal to integrate all other systems to DHIS2. Therefore, existing systems have a great influence on the design and management of health information systems' interoperability, as expressed in the following respondent verbatim quotes:

"Yeah we looked at other systems." "...of course there were systems that were running like open MRS but they were specific to programs. They were not general, that is when we opted to design our own health management system."

\subsection{Resources}

To have successful interventions and system sustainability, stable resources are required. These resources could include money, labour and time among others. For HIS interoperability implementation projects having skilled system developers and experienced top managers would be rewarding [68]. Managers and systems developers would work collaboratively for the success of the HIS interoperability implementation project. [68] refers to a successful HIS interoperability intervention where managers worked closely with system designers and vendors. For example in Uganda at the national level, the authorities have planned for interoperability, but at the implementation level these authorities are missing and have not managed the design of 
interoperability. As a result a number of silos HIS have been developed independently [46] with no or limited reference to the national interoperability architecture that is under construction. It is therefore, not enough for the authorities to issue a directive on interoperable systems, but rather they should supervise and enforce strict adherence to the recommended HIS interoperability implementation guidelines. In addition, the available staff should be skilled and should be able to carry out their roles effectively, though this is still a challenge in Uganda. The following respondent verbatim quotes point human resources as an important factor for the design and management of HIS interoperability.

"...there is a lot of things that need to be thought thru ...policies and other players say human resource and all that to deal with interoperability." "Human recourse in Uganda is still lacking a lot when it comes to technology empowerment."

On the other hand, another important resource is having enough money to finance all project activities [17, 68] as need arises. For example, a number of HIS implementations in Uganda are donor funded and are not sustainable once the project ends. Most of these donor-funded projects are disease specific e.g HIV-AIDS, so they focus on a narrow problem and lead to a pool of fragmented HIS all over the country, as reflected in the following respondent quote.

“..However, that RX-solution doesn't have an API, doesn't talk to macs \& sage....we have asked how come they are not interoperable,....this is given by the donor and they are not willing to integrate."

It implies that having enough money to implement and sustain inclusive interoperable HIS, might eliminate standalone disease specific systems. Yet, implementing inclusive interoperable HIS is very costly, and the health institutions are not ready to bear that high cost as seen in the following respondent verbatim quotes.

“...because you see the cost of integration is going to be borne by the facilities..... I do not think they have been able to quantify the exact benefit. "It would not actually be hard...I think it is an issue of resources not being allocated to that."

In other words, HIS interoperability implementations within a country could increase once a country's digital healthcare system is centrally driven and financed by the government. As seen in the five countries investigated by [69] that have employed a centralised mechanism of coordination, legislation and management of all their healthcare services. Therefore, cost and human resources highly influence HIS interoperability implementations.

\section{DISCUSSION}

This study presents a number of contextual factors that can influence HIS interoperability implementations, and further discusses their levels of controllability, as emphasised by [70]. Particularly, in this study some of the identified factors were controlled to some degree yet others could not be controlled at the implementation level -they were a 'must' follow [70]. The degree of controllability could be attributed to isomorphism forces, which according to [38] include coercive, normative and memetic institutional forces. With such forces at play sometimes, organizations live in what [71] refer to as an iron cage. For instance, in this case-study internal factors that were determined locally at the institutional level or by the implementation team could be controlled, but external factors were not feasibly controllable. External factors were primarily influenced by coercive forces and internal factors were primarily influenced by normative and memetic forces. 
Coercive forces could include national, international, or institutional policies, norms, values [38], standard operating procedures as well as national system implementation guidelines, which health institutions have to adhere to. In this study, coercive external factors included policy, interoperability standards, HIS implementation guidelines and existing health information systems. These were followed as is with exception of 'existing health information systems' that could be manipulated by the implementers, through human agency [72] and enactment [73]. Whereas internal factors included intended system goals, existing health information systems, resources and institutional autonomism, which were greatly manipulated by the HIS implementers. It is therefore important to understand beforehand the kind of contextual factors that might affect the HIS implementation process in order to mitigate them accordingly. As it is likely that the implementers will have limited or no control on external factors but can fully control the internal factors, for optimal management and design of health information systems' interoperability. However, depending on the prevailing conditions and the degree of controllability a given contextual factor can either hinder or enable intervention success [23, 24]. For example, when the initial system goals, policies, standards, and HIS interoperability implementation guidelines are in support of HIS interoperability, the developed systems are often interoperable else they are non-interoperable. At the same time when there are enough recourses in terms of money and skilled labour the HIS interoperability intervention would be successful else it would be negatively affected [68]. Yet again when existing HIS have attained a certain degree of interoperability maturity, then HIS interoperability implementations could be feasibly negotiated and enhanced.

Consequently, this study highlights the importance of context awareness and readiness, since awareness of the likely influence of certain contextual factors and their degree of controllability beforehand would prepare the system implementers $[55,70]$ on how to design and manage HIS interoperability. For instance, in situations where organisations live in what [71] calls a 'cage', organizations can be empowered and prepared to overcome the prevailing institutional logics, and pressures.

\section{CONCLUSION AND FUTURE WORKS}

This study intended to investigate contextual factors that influence the design and management of HIS interoperability. Expediently, a number of contextual factors including institutional autonomism, intended system goals, existing health information systems, national HIS implementation guidelines, interoperability standards, policy and resources were arrived at. However, due to institutional isomorphism, external contextual factors are not feasibly controllable at the project implementation level, but internal factors could be controlled. The study holds that contextual factors could either enable or hinder HIS interoperability implementations. Therefore, awareness of the likely contextual factors beforehand would greatly improve HIS' interoperability design and management. In conclusion, the study proposes the following as future works: (a) a focus on contextual factors in HIS interoperability design and management. (b) A focus on institutionalising laws, frameworks, guidelines, standards and policies that support HIS integration [64]. (c) Investigation of the potential of institutional lens in making sense of the institutions' context of integration, in order to discover salient factors that might affect HIS' interoperability designing. 


\section{REFERENCES}

[1] Heavin, C., Health Information Systems-Opportunities and Challenges in a Global Health Ecosystem. Journal of the Midwest Association for Information Systems| Vol, 2017. 2017(2): p. 1.

[2] Demirci, U., S. Wang, and F. Inci, Editorial for Advanced Health Care Technologies. Advanced Health Care Technologies, 2015. 1: p. 1-2.

[3] Demiris, G., et al., Patient-centered applications: use of information technology to promote disease management and wellness. A white paper by the AMIA knowledge in motion working group. J Am Med Inform Assoc, 2008. 15(1): p. 8-13.

[4] Bodenheimer, T., Coordinating care-a perilous journey through the health care system. 2008, Mass Medical Soc.

[5] Coleman, E.A., Falling through the cracks: challenges and opportunities for improving transitional care for persons with continuous complex care needs. Journal of the American Geriatrics Society, 2003. 51(4): p. 549-555.

[6] Kobusinge, G., et al. The (Missing?) Role of Health Information Systems (HIS) in Patient Care Coordination and Continuity (PCCC): The Case of Uganda. in International Conference on eInfrastructure and e-Services for Developing Countries. 2018. Springer.

[7] HIMSS, Dictionary of Healthcare Information Technology Terms, Acronyms and Organizations, p. 75. 3rd ed. 2013.

[8] Adenuga, O.A., R.M. Kekwaletswe, and A. Coleman, eHealth integration and interoperability issues: towards a solution through enterprise architecture. Health information science and systems, 2015. 3(1): p. 1-8.

[9] Bygstad, B., O. Hanseth, and D.T. Le. From IT Silos to Integrated Solutions. A Study in E-Health Complexity. in ECIS. 2015.

[10] Weber-Jahnke, J., L. Peyton, and T. Topaloglou, eHealth system interoperability. Information Systems Frontiers, 2012. 14(1): p. 1-3.

[11] Adebesin, F., et al., A review of interoperability standards in e-Health and imperatives for their adoption in Africa. South African Computer Journal, 2013. 50(1): p. 55-72.

[12] Kuziemsky, C.E. and J.H. Weber-Jahnke, An ebusiness-based framework for ehealth interoperability. Journal of Emerging Technologies in Web Intelligence, 2009. 1(2): p. 129-136.

[13] Abbott, P.A., et al., Complexity and the science of implementation in health IT - knowledge gaps and future visions. International journal of medical informatics, 2014. 83(7): p. e12-e22.

[14] Barbarito, F., et al., Implementing standards for the interoperability among healthcare providers in the public regionalized Healthcare Information System of the Lombardy Region. Journal of biomedical informatics, 2012. 45(4): p. 736-745.

[15] Kobusinge, G., et al. An Implementation Process of Interoperability: A Case-Study of Health Information Systems (HIS). in Designing Digitalization, ISD. 2018. Lund, Sweden.

[16] Ludwick, D.A. and J. Doucette, Adopting electronic medical records in primary care: lessons learned from health information systems implementation experience in seven countries. International journal of medical informatics, 2009. 78(1): p. 22-31.

[17] Axelsson, K. and U. Melin. Contextual Factors Influencing Health Information Systems Implementation in Public Sector-Investigating the Explanatory Power of Critical Success Factors. in International Conference on Electronic Government. 2014. Springer.

[18] Brown, N. and I. Brown. Contextual factors influencing strategic information systems plan implementation. in Proceedings of the South African Institute of Computer Scientists and Information Technologists Conference on Knowledge, Innovation and Leadership in a Diverse, Multidisciplinary Environment. 2011. ACM.

[19] Carvalho, J.V., Á. Rocha, and A. Abreu, Maturity models of healthcare information systems and technologies: a literature review. Journal of medical systems, 2016. 40(6): p. 131.

[20] Coles, E., et al., The influence of contextual factors on healthcare quality improvement initiatives: what works, for whom and in what setting? Protocol for a realist review. Systematic reviews, 2017. 6(1): p. 168.

[21] Cucciniello, M., et al., Understanding key factors affecting electronic medical record implementation: a sociotechnical approach. BMC health services research, 2015. 15(1): p. 268. 
[22] Dopson, S., L. Fitzgerald, and E. Ferlie, Understanding change and innovation in healthcare settings: reconceptualizing the active role of context. Journal of change management, 2008. 8(3-4): p. 213231.

[23] Ogrinc, G., et al., SQUIRE 2.0 (Standards for QUality Improvement Reporting Excellence): revised publication guidelines from a detailed consensus process. The Journal of Continuing Education in Nursing, 2015. 46(11): p. 501-507.

[24] Gichoya, D., Factors affecting the successful implementation of ICT projects in Government. 2005.

[25] Hugoson, M.-̊., T. Magoulas, and K. Pessi, Interoperability strategies for business agility, in Advances in enterprise engineering I. 2008, Springer. p. 108-121.

[26] Novakouski, M. and G.A. Lewis, Interoperability in the e-Government Context. 2012, CARNEGIEMELLON UNIV PITTSBURGH PA SOFTWARE ENGINEERING INST.

[27] Solotruk, M. and M. Krištofič, Increasing the degree of information system integration and developing an integrated information system. Information \& Management, 1980. 3(5): p. 207-212.

[28] Ullah, F., et al., Semantic interoperability for big-data in heterogeneous IoT infrastructure for healthcare. Sustainable Cities and Society, 2017. 34: p. 90-96.

[29] Manda, M.I. and J. Backhouse. An analysis of the barriers to e-government integration, interoperability and information sharing in developing countries: A systematic review of literature. in Proceedings of the African Conference in Information Systems and Technology, Accra, Ghana. 2016.

[30] Pettigrew, A.M., Context and action in the transformation of the firm: A reprise. Journal of Management studies, 2012. 49(7): p. 1304-1328.

[31] Rauffet, P., C. Da Cunha, and A. Bernard. Designing and managing Organizational Interoperability with organizational capabilities and roadmaps. in Interoperability for Enterprise Software and Applications China, 2009. IESA'09. International Conference on. 2009. IEEE.

[32] Harvey, F., Designing for interoperability: Overcoming semantic differences, in Interoperating Geographic Information Systems. 1999, Springer. p. 85-97.

[33] Braa, J., et al., Developing health information systems in developing countries: the flexible standards strategy. Mis Quarterly, 2007: p. 381-402.

[34] Scott, W.R., Institutions and Organizations. 2nd ed ed. Vol. 2nd ed. 2001: Thousand Oaks, CA: Sage, 2nd ed.

[35] Scott, W.R., Institutional theory: Contributing to a theoretical research program. Great minds in management: The process of theory development, 2005. 37(2005): p. 460-484.

[36] Bjorck, F. Institutional theory: A new perspective for research into IS/IT security in organisations. in 37th Annual Hawaii International Conference on System Sciences, 2004. Proceedings of the. 2004. IEEE.

[37] Luna-Reyes, L.F., J.R. Gil-Garcia, and C.B. Cruz, Collaborative digital government in Mexico: Some lessons from federal Web-based interorganizational information integration initiatives. Government Information Quarterly, 2007. 24(4): p. 808-826.

[38] DiMaggio, P.J. and W.W. Powell, The iron cage revisited: Institutional isomorphism and collective rationality in organizational fields. American sociological review, 1983: p. 147-160.

[39] Hjort-Madsen, K. Enterprise architecture implementation and management: A case study on interoperability. in System Sciences, 2006. HICSS'06. Proceedings of the 39th Annual Hawaii International Conference on. 2006. IEEE.

[40] Creswell, J.W., Research Design: Qualitative, Quantitative and Mixed Method Approaches 3rd ed. 2009, Los Angeles: SAGE Publications.

[41] Rowlands, B., Employing interpretive research to build theory of information systems practice. Australasian Journal of Information Systems, 2003. 10(2).

[42] Thomas, G., A typology for the case study in social science following a review of definition, discourse, and structure. Qualitative inquiry, 2011. 17(6): p. 511-521.

[43] Cibangu, S.K., Qualitative research: The toolkit of theories in the social sciences, in Theoretical and methodological approaches to social sciences and knowledge management. 2012, InTech.

[44] Thomas, D.R., A general inductive approach for analyzing qualitative evaluation data. American journal of evaluation, 2006. 27(2): p. 237-246.

[45] Mukasa, N., Uganda Healthcare system profile: background, organization, polices and challenges. J Sustain Reg Health Syst, 2012. 1: p. 2-10.

[46] Kiberu, V.M., M. Mars, and R.E. Scott, Barriers and opportunities to implementation of sustainable e-Health programmes in Uganda: A literature review. African Journal of Primary Health Care and Family Medicine, 2017. 9(1): p. 1-10. 
[47] Omaswa, C. UGANDA NATIONAL EHEALTH STRATEGIC PLAN 2012/2013 - 2014/2015 2012 [cited 2018 20/06]; Available from: http://www.ubts.go.ug/assets/publications/Uganda\%20National\%20eHealth\%20Strategic\%20Plan_A pril\%202013.pdf.

[48] Kanagwa, B., J. Ntacyo, and S. Orach, Towards Paperless Hospitals: Lessons Learned From 15 Health Facilities In Uganda, in New Advances in Information Systems and Technologies. 2016, Springer. p. 23-32.

[49] Walsham, G., Doing interpretive research. European journal of information systems, 2006. 15(3): p. 320-330.

[50] Hennink, M., I. Hutter, and A. Bailey, "Data preparation and developing code", Chapter 9 in "Qualitative Research Methods", SAGE Publications, pp. 203-232. . 2010: Sage.

[51] Van Lamsweerde, A. Goal-oriented requirements engineering: A guided tour. in Proceedings fifth ieee international symposium on requirements engineering. 2001. IEEE.

[52] Rothenberg, J., Interoperability as a semantic cross-cutting concern. Interoperabiliteit: Eerlijk zullen we alles delen,. 2008.

[53] Salas, P.E., et al. Interoperability by design using the StdTrip tool: an a priori approach. in Proceedings of the 6th International Conference on Semantic Systems. 2010. ACM.

[54] Adebesin, F., et al., Barriers \& challenges to the adoption of E-Health standards in Africa. 2013.

[55] Luna, D., et al., Health informatics in developing countries: going beyond pilot practices to sustainable implementations: a review of the current challenges. Healthcare informatics research, 2014. 20(1): p. 3-10.

[56] ISO, Interoperability of telehealth systems and networks- - Part 1: Introduction and definitions, in ISO/TR 16056-1:2004 Health informatics -- 2004.

[57] Commission, E., New European interoperability framework. Promoting seamless services and data flows for European public administrations. 2017, Publications Office of the European Union Luxembourg.

[58] Mu-Hsing Kuo, A. Kushniruk, and B. Elizabeth, A Comparison of National Health Data Interoperability Approaches in Taiwan, Denmark and Canada. ElectronicHealthcare, 2011. 10(2): p. e14-e25.

[59] HIQA, Overview of Healthcare Interoperability Standards, Health Information and Quality Authority 2013.

[60] Berre, A.J., et al., The ATHENA interoperability framework. In Enterprise interoperability II (pp. 569-580). Springer London. 2007.

[61] Svensson, A., Challenges in Using IT Systems for Collaboration in Healthcare Services. International journal of environmental research and public health, 2019. 16(10): p. 1773.

[62] Meyer, J.W. and B. Rowan, Institutionalized organizations: Formal structure as myth and ceremony. American journal of sociology, 1977. 83(2): p. 340-363.

[63] Lowi, T.J., Four systems of policy, politics, and choice. Public administration review, 1972. 32(4): p. 298-310.

[64] Juzwishin, D.W. Political, policy and social barriers to health system interoperability: emerging opportunities of Web 2.0 and 3.0. in Healthcare management forum. 2009. SAGE Publications Sage CA: Los Angeles, CA.

[65] IEEE, (Institute of Electrical and Electronics Engineers).: Standard computer dictionary a compilation of IEEE standard computer glossaries. 1990.

[66] Chen, D., G. Doumeingts, and F. Vernadat, Architectures for enterprise integration and interoperability: Past, present and future. Computers in industry, 2008. 59(7): p. 647-659.

[67] Mosweu, O., K.J. Bwalya, and A. Mutshewa, A probe into the factors for adoption and usage of electronic document and records management systems in the Botswana context. Information development, 2017. 33(1): p. 97-110.

[68] Kobusinge, G. "Putting Interoperability on Health-information-systems' Implementation Agenda." in In Proceedings of the 53rd Hawaii International Conference on System Sciences. 2020.

[69] Carnicero, J. and D. Rojas, Application of information and communication technologies for health systems in Belgium, Denmark, Spain, the United Kingdom and Sweden. 2010: ECLAC.

[70] Olbrich, S., J. Poppelbuß, and B. Niehaves. Critical contextual success factors for business intelligence: A Delphi study on their relevance, variability, and controllability. in 2012 45th Hawaii International Conference on System Sciences. 2012. IEEE. 
[71] Jensen, T.B., A. Kjærgaard, and P. Svejvig, Using institutional theory with sensemaking theory: a case study of information system implementation in healthcare. Journal of Information Technology, 2009. 24(4): p. 343-353.

[72] Orlikowski, W.J., The duality of technology: Rethinking the concept of technology in organizations. Organization science, 1992. 3(3): p. 398-427.

[73] Weick, K., Sensemaking in organizations Sage Publications. Thousand Oaks, CA, 1995.

\section{AUTHOR}

Grace Kobusinge, Health Informatics PhD Candidate, Faculty of Applied IT, Informatics Department, University of Gothenburg-Sweden, Assistant Lecturer, Department of Information Systems, College of Computing and Information Science, School of Computing and IT, Makerere University Uganda. Research areas of interest: ICT4D, Health informatics, Health information systems' interoperability, knowledge management and human computer interaction.

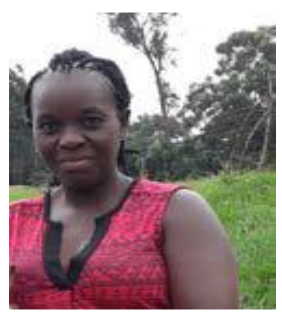

(C) 2020 By AIRCC Publishing Corporation. This article is published under the Creative Commons Attribution (CC BY) license. 